\title{
EL SISTEMA DE AFP CHILENO: UNA VISIÓN CRÍTICA
}

\section{Ricardo Hormazábal S. Universidad de Chile}

\begin{abstract}
"En un mes cualquiera, (en Chile) el 40\% de los trabajadores no realiza aportes al sistema Previsional. Si este patrón continúa, en el año 2030 es probable que solo alrededor del $45 \%$ de los trabajadores afiliados reciba beneficios superiores a la pensión mínima estatal.

"Las Administradoras de fondos han percibido utilidades persistentemente altas con un retorno anual sobre el patrimonio del $30 \%$ en promedio en los años recientes, el doble de los bancos comerciales" (BM, 2006)
\end{abstract}

\section{Resumen}

El artículo presenta una visión crítica al sistema previsional chileno, la que se sustenta en tres hipótesis propuestas por el autor. La primera plantea que el sistema previsional basado en las AFP no surgió para superar las deficiencias del antiguo sistema de reparto, sino que por otros intereses, de orden político. La segunda sostiene que el sistema de AFP entrega pensiones exiguas para mayoría de los afiliados y no cumple con las disposiciones internacionales y nacionales sobre la materia. La última hipótesis afirma que el sistema ha colaborado a la concentración de la riqueza, a la desigual distribución del ingreso Finalmente, el artículo propone dieciséis propuestas para encaminar el debate de reforma previsional que se desarrolla actualmente en Chile.

Palabras Claves: Sistema Previsional Chileno, Reforma Previsional, Propuestas Alternativas

\section{Abstract}

The paper presents a critical vision of the Chilean pensions system (AFP), which is rooted in three hypotheses. In the first place, it is suggested that the AFP system was created to benefit political interests and not as a way to repair the problems of the former system. The second hypothesis proposes that the AFP system does not follow international pension systems standards and that it delivers poor pensions to the majority of the affiliated members. Thirdly, the paper contends that the AFP system has contributed to national wealth concentration and favors national income concentration. The article concludes with sixteen specific proposals to address the present debate on reforming the Chilean system.

Keywords: Chilean Pensions System, Pensions System Reform, Alternative Reform Proposals 


\section{Introducción}

La discusión de esta materia forma parte, principalmente, de un debate político, como lo señaló la Presidenta Bachelet el 28.09.del 2006: "Esta es en esencia, una discusión política, con alto contenido técnico, sin duda, porque habrá mejores respuestas que otras, pero esencialmente política". En 1980, año en que se impone el sistema de las Administradoras d Fondos de Pensiones (AFP), también se le asignaba un carácter político, casi doctrinario. El ideólogo del sistema, José Piñera escribió: "Una Reforma Previsional tan liberal como la que proyectábamos, tuvo muchos detractores. Don Jorge era un gran partidario de la empresa privada, pero no era un liberal. Don Jorge era capitalista en lo económico, pero era estatista en lo social" (Piñera, 1991: 29). El personaje aludido por Piñera era don Jorge Alessandri Rodríguez, ex Presidente de Chile entre 1958 y 1964, miembro del Consejo de Estado que asesoraba a la Junta Militar.

La publicación de este artículo surge en medio de las discusiones generadas por la ineficiente implementación del sistema de transporte metropolitano denominado Transantiago y que presenta similitudes con el sistema de AFP, ya que se hizo por algunos funcionarios públicos para darle un buen negocio a los privados, usando como excusa la necesidad de cambiar un sistema malo. Se gestó, también, entre cuatro paredes, ha provocado un gasto público estratosférico, 25 veces mayor que el Transantiago al año, durante 25 años, un cuarto de siglo, ha humillado a millones de trabajadores y no proporciona pensiones dignas.

Pero las diferencias son también muy significativas. El desastre en el transporte es comentado en todos los medios de comunicación, de manera muy intensa, y el tema previsional se oculta. También es diferente la magnitud del impacto negativo en la población y la fuerza que el sistema de AFP le otorga a los grandes grupos empresariales para controlar la economía e influir en la política nacional.

La ardua y mediática discusión parlamentaria sobre el aporte extra de U\$290.000.000 para evitar el alza de las tarifas en el sistema de transporte contrasta con el casi inexistente debate sobre el déficit previsional anual que alcanza a un $5 \%$ del PIB en promedio, alrededor de U\$7.000.000.000 anuales (BM, 2006) y que en un porcentaje significativo son retenidos por los grandes y poderosos grupos que las controlan. Recientemente, la Subsecretaria de Previsión ha denunciado con fuerza las imposiciones no pagadas por muchos empleadores y que se cuantifica en una cifra cercana a los U\$ 400.000 .000 , lo que los Tribunales de Justicia han calificado como delito de apropiación indebida.

En el próximo punto se discutirán los principales conceptos que permiten seguir la discusión que se desarrollará. Con posterioridad se muestran los antecedentes históricos que tiene la 
previsión social. En la cuarta sección se presentan tres hipótesis para entender el modelo de AFP seguido en Chile y; finalmente, se plantean dieciséis puntos para nutrir al debate sobre el proyecto de reforma previsional que se discute actualmente en Chile.

\section{Conceptos esenciales para una discusión}

\subsection{Seguridad Social}

La seguridad social "es la protección que ofrece una sociedad a personas y hogares., destinada a garantizar el acceso a la asistencia sanitaria y la seguridad de lo ingresos, particularmente en situaciones de edad avanzada, desempleo, enfermedad, discapacidad, lesión profesional, maternidad o pérdida del sostén de la familia" (OIT, 2002).

La Conferencia de la OIT del año 2001 declaró que los regímenes de Seguridad Social "deberían administrarse de forma sana y transparente, con costos administrativos tan bajos como sea factible y una fuerte participación de los interlocutores sociales" (OIT, 2002). Ratificó la participación eficaz y con un papel importante de dichos interlocutores en el desarrollo de políticas y en los órganos bipartitos (trabajadores y empleadores) o tripartitos (los anteriores más el gobierno) de gestión de la seguridad social. Identificó la mejora del gobierno y la administración de la seguridad social como temas prioritarios en la investigación, reuniones de expertos y cooperación técnica. Por último recomendó el diálogo social de los tres sectores con el fin de generar consenso social y voluntad política para actuar, especialmente cuando se debata una reforma del sistema.

De este modo queda en evidencia que las políticas de seguridad social tienen que ver con una visión solidaria de la sociedad y que buscan la satisfacción de las necesidades en casos de producirse la contingencia que la genera, favoreciendo además el enfoque redistributivo. Este último carácter es negado enfáticamente por los partidarios del sistema de AFP chileno, que lo conciben como una industria más, en la que los que tienen más pueden comprar los mejores productos y los que lo administran pueden obtener las mayores utilidades, sin preocupación mayor por el destino de los que podríamos denominar "consumidores de pensiones". La redistribución, si se quiere abordar, se debería hacer mediante el sistema de impuestos.

\subsection{Principios de la Seguridad Social}

La mayor parte de los autores consideran que son principios inherentes a la Seguridad Social, los siguientes (Novoa, 1997).

\subsubsection{Universalidad}

La Seguridad Social debe proteger a todas las personas de todos los riesgos o contingencias 
sociales, amparando cada uno de los estados de necesidad producidos. Algunos autores distinguen entre universalidad subjetiva y universalidad objetiva: La primera se refiere a la protección de las personas, de modo que, de acuerdo a esta concepción, la Seguridad Social debe proteger a toda la población, sin que existan discriminaciones o limitaciones a causa de la edad, raza o nacionalidad de los individuos; ni tampoco en razón de su calidad de trabajadores dependientes o independientes, o de percibir una remuneración superior 0 inferior a un determinado límite. La universalidad objetiva, se ubica en la perspectiva de los riesgos concretos y persigue que la seguridad social otorgue cobertura frente a todas las contingencias sociales, esto es, cesantía, enfermedad, accidente, siniestros profesionales, invalidez, vejez, muerte e incremento familiar.

\subsubsection{Integralidad}

La Seguridad Social debe otorgar todo tipo de prestaciones destinadas a satisfacer todos y cada uno de los estados de necesidad. Los montos de las prestaciones deben ser suficientes y apropiados para cubrir satisfactoriamente el estado de necesidad, y adecuadas a la naturaleza de éste.

\subsubsection{Solidaridad}

La Seguridad Social es un esfuerzo de toda la comunidad, al cual deben contribuir todos sus componentes y cada uno según sus capacidades y posibilidades, ya que se reconoce que ocurren ciertos hechos que generan un estado de necesidad, el que no puede ser superado aisladamente por el individuo. La pertenencia de la persona a la sociedad adquiere aquí una visibilidad notable, lo que hace imprescindible distribuir los efectos económicos de las contingencias entre un mayor número de personas, concretando de este modo el deber de ayudarse mutuamente frente a la adversidad.

\subsubsection{Uniformidad}

Este principio también es conocido como el de unidad, y se expresa en que un mismo estado de necesidad debe cubrirse con una prestación similar, existiendo iguales requisitos. En tal virtud, la Seguridad Social no admite discriminaciones ni en la calidad de las prestaciones ni en los requisitos que se exigen para adquirir derecho a ellas, exigiendo por ende armonía, coherencia y unidad del sistema establecido, el que debe contar con un sistema dotado de normas objetivas y sometidas a un adecuado control.

\subsubsection{Subsidiariedad}

Este principio supera el ámbito propio de la Seguridad Social, corresponde a un determinado enfoque de la estructura política, económica y social que, en este ámbito epecífico, postula 
que el individuo es el primer responsable de su seguridad y la de su grupo familiar, para lo cual se procura medios económicos, a través de su trabajo o de la cobertura que le proporciona el grupo social intermedio al que pertenece. En este contexto, la participación del Estado cobra importancia cuando la capacidad económica del individuo y/o de su grupo no permite cumplir el fin de cobertura.

\subsubsection{Internacionalidad}

En virtud de este principio, la protección al individuo debe otorgarse independientemente del Estado en que se encuentre residiendo, superando así, las fronteras con el solo fin de proteger al individuo -nacional o extranjero- que se encuentra en estado de necesidad.

\subsection{Los principios actuales de la OIT}

Según la OIT, los principios que deben regir la seguridad social, manifestados tras el año 2001, son los siguientes:

- No existe un modelo idóneo único de seguridad social, pero el Estado debe tener la función prioritaria para facilitar, promover y extender la cobertura.

- Los sistemas de seguridad social no solamente deben ofrecer trato igual para hombres y mujeres sino también asegurar resultados equitativos para las mujeres.

- Los sistemas de cuentas de ahorro individuales, donde las propias personas asumen el riesgo, no deberían debilitar los sistemas de solidaridad.

- Los sistemas de pensiones obligatorias deben garantizar beneficios adecuados y asegurar la solidaridad nacional.

- Hacer presente que todo proceso de reforma, más aún cuando se hace en democracia, exige un diálogo social de verdad (0IT, 2002).

El año 2001 se produjo un cambio en la posición tradicional de la OIT, influida por las concepciones más liberales flexibilizó sus posiciones anteriores, que en el caso de Chile y el sistema de AFP habían llevado a sucesivas resoluciones condenatorias del sistema. Los informes de la Comisión de Expertos en Aplicación de Convenios y Recomendaciones de los años 1992, 1993 y 1995, solicitaban a Chile "enmendar el DL [Decreto Ley] 3.500 para que el seguro de pensiones sea administrado por instituciones que no persigan ningún fin lucrativo" (OIT, 1993: 127), lo que no se hizo ni en dictadura ni en democracia.

\section{Antecedente históricos de la Previsión Social}

Los especialistas reconocen ya en la antigua Roma, los Colegios, que en los primeros siglos de nuestra era, eran entidades de cooperación ante contingencias de sus integrantes, 
posteriormente las Cofradías y las diaconías, fuertemente influidas por los cristianos, entregaban ciertas prestaciones. Le siguieron las Hermandades de Socorros en el siglo XVI, los Montes de Piedad o Montepíos en el siglo XVIII. El 14 de Junio de 1791 se dicta la denominada Ley Chapelier que aplica la prohibición de existencia de todas las corporaciones. Su principal impulsor sostenía que era a la nación, a los funcionarios públicos, "a los que les correspondía proporcionar trabajo a quienes lo necesiten para su existencia y socorro a los enfermos" (Novoa, 1977: 19).

Para Novoa (1977: 21) Otto von Bismarck, Canciller alemán del siglo XIX, fue el "verdadero padre de la Seguridad Social", ya que bajo su mandato se dictaron las leyes sobre seguro de enfermedad (15 de julio de 1883), accidentes del trabajo ( 6 de julio de 1884) y seguro de invalidez y sobrevivencia (22 de Junio de 1889), así como normas que impedían la actividad de las organizaciones de trabajadores. William Beveridge, académico de Oxford, es considerado uno de los precursores de la Seguridad Social del siglo XX. Un informe preparado bajo su dirección, fue aprobado con modificaciones por el Parlamento inglés el 20 de Junio de 1942, lo que permitió poner en vigencia leyes sobre subsidios familiares en 1945, accidentes del trabajo, seguros sociales y servicios de salud, en 1946. En 1948 se dictan leyes sobre seguro accidentes del trabajo, previsión y asistencia nacional.

En Chile, fue Pedro de Valdivia el que fundó el primer hospital, el 3 de octubre de 1552, conocido como Nuestra Señora del Socorro y, posteriormente, como Hospital San Juan de Dios. En 1832 se organizó la Junta General de Beneficencia y Salud Pública; en 1852 se fundó el Manicomio Nacional. En 1855 se dicta la primera Ley sobre montepío militar y el 19 de Junio de 1858 se fundó la caja de Ahorros de Empleados Públicos. El 20 de febrero de 1906 se dicta la ley 1838 sobre Habitaciones para Obreros; en 1911 la ley 2.498 creó la Caja de Ahorro de los empleados de ferrocarriles y las leyes 3.020 y 3.045 del año 1915, establecieron la Caja de Retiro y Montepío de las Fuerzas Armadas. Ese mismo año, se había dictado la ley 2.951, denominada ley de la silla, establecida para que los trabajadores del comercio tuvieran oportunidad de descansar, norma que incluso en este siglo XXI, no es respetada por muchos empleadores. La primera ley sobre accidentes del trabajo fue la 3.170 de 1916. El descanso dominical fue consagrado en la ley 3.321 de 1917. En medio de la efervescencia social y militar, se dictan el 8 de septiembre de 1924, 7 leyes: 4.053, sobre Contrato de Trabajo de Obreros; 4.054, sobre Seguro Obrero Obligatorio de Invalidez, Enfermedad y Vejez; 4.055, estableció una Indemnización por Accidentes del Trabajo: 4.056 sobre tribunales de Conciliación y Arbitraje; 4.057, sobre Organización Sindical; 4.058 sobre Cooperativas y 4.059, que legisló sobre Contrato de Empleados Particulares y estableció un Fondo de Retiro (Novoa, 1977). 
Las primeras concreciones en materia de Seguridad Social en Chile hicieron de nuestro país un pionero en América Latina sobre estas materias tan vitales. En 1968 se dictaron dos cuerpos legales que nos hicieron, una vez más, ir a la vanguardia en Seguridad Social: La ley 16.744 sobre Accidentes del Trabajo y Enfermedades Profesionales y la Ley 16.781 sobre Medicina Curativa para los Empleados Particulares, hoy el Fondo Nacional de Salud (FONASA).

En 1979 existían un total de 32 instituciones, lo que dio origen a más de cien regímenes previsionales diferentes, llevando a una gran desigualdad entre los beneficios de las distintas instituciones prestadoras de este servicio. De las 32 entidades existentes, eran tres las principales, el Servicio de Seguro Social (SSS), la Caja de Previsión de Empleados Particulares (EMPART) y la Caja Nacional de Empleados Públicos y Periodistas (CANAEMPU) las que, en conjunto, abarcaban en 1980, un $94 \%$ del total de imponentes. A partir de los años cincuenta, distintos gobiernos promovieron estudios y análisis sobre el Sistema Previsional.

Desde el gobierno de Carlos Ibáñez (1952-1958), pasando por los gobiernos de Jorge Alessandri (1958-1964) y Eduardo Frei Montalva (1964-1970) los análisis realizados mostraron como principales conclusiones las siguientes:

- El Sistema Previsional resultaba muy costoso para trabajadores y empleadores;

- La existencia de numerosas Cajas implicaba una administración cara e ineficiente;

- Las pensiones sufrían significativas desvalorizaciones por efectos de la inflación;

- No existía un orden preestablecido en cuanto al financiamiento de los servicios y los beneficios otorgados;

- El Sistema era discriminatorio, dados los diferentes requisitos para afiliarse, tasas de cotización, conceptos para determinar invalidez, servicios prestados y mecanismos de reajustabilidad de las pensiones;

- No cubría a la totalidad de los trabajadores,

- Los recursos eran insuficientes y

- Disminuía fuertemente el número de activos en relación con el aumento de los pasivos.

Las tasas de imposiciones sobre sueldos y salarios fueron aumentando en el tiempo llegando en 1974 a representar más de un $50 \%{ }^{1}$ de la remuneración mensual del trabajador, pero la mayor parte era aporte del empleador. Posteriormente estas tasas, comienzan a reducirse paulatinamente, lo que aumentó las dificultades de financiamiento del Sistema. Cabe destacar que esta tasa de cotización global financiaba pensiones, prestaciones de salud y accidentes del trabajo, entre otros.

\footnotetext{
1 Esta tasa incluye las cotizaciones cobradas por concepto de pensiones, salud, accidentes del trabajo y otros.
} 
Muchos ignoran que el Sistema Previsional antiguo inicialmente funcionaba como un Sistema de Capitalización Parcial, es decir, los imponentes activos financiaban las pensiones de los pasivos, pero a la vez, estas entidades constituían reservas financiadas con una parte de los recursos recaudados. Paulatinamente esta opción fue debilitándose, transformándose en un Sistema de Reparto simple, es decir, sin acumulación de reservas. A fines de los años sesenta, cerca del $65 \%$ de los ingresos totales de las Cajas de Previsión el Sistema Previsional Antiguo provenían de las cotizaciones efectuadas por trabajadores y empleadores, con las cuales se financiaban pensiones, asignaciones familiares, prestaciones por enfermedad y accidentes del trabajo y subsidios de cesantía. El aporte del Estado era cercano al 30\% del total de los ingresos. El saldo restante provenía del rendimiento de las inversiones y otros. Con el transcurso de los años las recaudaciones no pudieron financiar los beneficios otorgados por las distintas Cajas, por lo cual se fueron aumentando las tasas de cotización y, siendo esto aún insuficiente, fue necesario incrementar los aportes del Estado.

\section{Tres hipótesis para entender el sistema de AFP chileno}

\subsection{El sistema previsional basado en las AFP no surgió para superar las graves deficiencias del antiguo sistema de reparto sino por miedo a la democracia.}

El propio José Piñera Echenique, que se desempeñó como Ministro del Trabajo del General Pinochet, ha escrito sobre el particular lo siguiente: "Para mucha gente el DL 2.448 de Febrero del 79 recogió todo lo que una reforma previsional podía contener en materia de metas y soluciones. Cristalizaba de la mejor manera las aspiraciones reformistas de Jorge Prat, Jorge Alessandri o Eduardo Frei M, ya que se basaba en principios de equidad, requisitos comunes para jubilar y reajustable por ley". De acuerdo a este personero, Ministro del Trabajo cuando se dictó el DL 2.448, "solo faltaba racionalizar un poco la administración de las cajas" para que se subsanaran todas la dificultades". Él mismo autor agregó: "Para un amplio sector de opinión, dentro y fuera del Gobierno de Pinochet, la Reforma debía llegar hasta ahí" (Piñera, 1991: 60-61). Un destacado profesional, de ideas distintas a las del señor Piñera escribió por su parte: "La solución de las deficiencias del antiguo sistema no requiere la introducción de un régimen de pensiones privado de capitalización individual" (Arellano, 1981: 6).

Si las graves deficiencias habían sido superadas eliminando, entre otras disposiciones especiales, las perseguidoras, sistema que beneficiaba a cerca de 120 mil personas que, estando pensionadas, veían incrementarse sus pensiones en la misma proporción que e reajustaba la de los funcionarios del mismo grado en actividad, ¿Por qué introducir un sistema completamente nuevo? Dejemos que conteste el propio ex Ministro del Trabajo del General 
Pinochet, José Piñera Echenique: "Un Gobierno militar podía dictar el DL 2.448, ¿Podría un gobierno democrático mantener estas normas bajo presión de los grupos de interés?" (Piñera, 1991: 61).

Los grupos de presión de la época sí tenían derecho a expresarse. Por eso las Fuerzas Armadas se mantuvieron hasta hoy en el sistema antiguo y los grandes sectores empresariales apoyaron la medida de eliminar el aporte patronal para previsión y emprendieron con gran entusiasmo la tarea de crear sociedades administradoras de pensiones, compañías de seguro y cientos de empresas relacionadas, para hacer uso del dinero de los trabajadores, sin participación alguna de sus propietarios. Resulta evidente que el sistema de AFP no surge a causa de las fallas del antiguo sistema, sino que se elabora para impedir que en una futura democracia se pudieran expresar otros grupos de presión que en el período dictatorial les estaba prohibido defender sus legítimos intereses.

\subsection{El sistema de AFP ha fracasado en sus fines de entregar pensiones dignas para la mayoría de los afiliados y no cumple con las disposiciones internacionales y nacionales sobre la materia}

José Piñera Echenique informaba a los chilenos que el nuevo sistema permitiría alcanzar pensiones equivalentes al 70\% del ingreso imponible (Piñera, 1991: 68-69). De acuerdo a los antecedente que publica la Superintendencia de Administradoras de Fondos Pensiones (SAFP), el ingreso imponible promedio en el mes de Agosto de 2006 era de $\$ 363.854$, de modo que para alcanzar porcentaje prometido por el ex Ministro del Trabajo las pensiones debían alcanzar a \$254.697,8 (SAFP, 2006a).

La misma SAFP publica que a ese mimo mes, hay 595.292 jubilados, con una pensión promedio de $\$ 147.605$ mensuales, lo que equivale al $40 \%$ del salario promedio y se ubica en el piso inferior a lo establecido en las normas de la OIT. Al desagregar datos y analizar el monto de las pensiones según la modalidad elegida por el beneficiario, podemos constatar que ese mes existían 347.007 pensiones con la modalidad de Rentas Vitalicias, con un promedio de $\$ 174.009$, equivalente a un $47 \%$ del ingreso promedio. En la modalidad de Retiro Programado existían 225.233 jubilados, con un promedio de $\$ 97.731$, lo que representaba un $27 \%$ del ingreso promedio, muy por debajo del piso de la OIT. Los pensionados que habían optado por jubilar anticipadamente, eran 231.259, y su pensión promedio era de $\$ 192.062$, lo que representaba el 52,7\% del ingreso promedio de Agoto del 2006. Sólo 30 personas de las 595.292 pensionadas del sistema de AFP, recibían una pensión de $\$ 722.623$ mensuales, un $198 \%$ del ingreso imponible (SAFP, 2006). 
La situación no cambia mucho de un año a otro. Al mes de Abril del 2007, el sistema de AFP paga 611.056 pensiones, con un promedio al mes de abril del 2007 de $\$ 150.992$ (SAFP, 2007c). Al desglosar esta cantidad de pensiones, 352.864 corresponden a la modalidad de Rentas Vitalicias y 235.849 a la modalidad de retiros programados. Para el primer caso, el promedio de pensiones sube a los $\$ 177.140$, y para el segundo baja a $\$ 102.196$. Además existen 83.226 pensiones pagadas con la garantía del Estado y que alcanzan a los $\$ 87.000$.

Cumpliendo un compromiso de campaña, la Presidenta Bachelet envió un proyecto que se convirtió en la Ley $N^{\circ}$ 20.101, publicada en el Diario Oficial del 5 de mayo de 2006, mediante el cual se reajustaron las pensiones de la siguiente manera:

- Pensionados menores de 70 años de edad que recibían $\$ 79.866,71$, pasaron a percibir $\$ 87.853,38$.

- Pensionados de 70 años y más, pero menores de 75 años de edad, cuyas pensiones eran de $\$ 87.328,10$ se reajustaron a la suma de $\$ 96.060,91$.

- Pensionados de 75 años de edad y más, que recibían pensiones de $\$ 93.176,14$ comenzaron a recibir \$102.493,75.

El Banco Mundial, estima que el sistema de AFP en el año 2030 generaría, que solo alrededor del $45 \%$ de los trabajadores afiliados reciba beneficios superiores a la pensión mínima estatal (BM, 2006). Por su parte, el Consejo Asesor Presidencial para la Reforma Previsional, o Comisión Marcel, integrada mayoritariamente por personeros partidarios del sistema de AFP concluyó: "De seguir las cosas como están, se estima que dentro de 20 años solo alrededor de la mitad de lo adultos mayores podrá contar con una pensión superior a la pensión mínima; menos de un $5 \%$ podrá acceder a la pensión mínima garantizada por el estado, actualmente \$87.853 mensuales". El resto deberá conformarse con pensión inferior a la mínima, una pensión asistencial "actualmente de $\$ 44.186$, una pensión de sobrevivencia o no tendrá pensión" (CARP, 2006: 7).

Pero hay una conclusión más directa que avala la segunda hipótesis que hemos presentado: "El régimen de capitalización creado por la Reforma de 1981 no es actualmente capaz de resolver las necesidades previsionales de los chilenos" (CARP, 2006: 17). La misma Comisión concluyó que la realidad de las AFP contrasta con las exigencias hacia el sistema previsional que surgen de lo convenios internacionales, de la Constitución y de las opiniones ciudadanas (CARP, 2006: 7).

\subsection{La concentración de la riqueza}

En una publicación del lunes 2 de julio, el diario La Tercera publica que el 1\% de los chilenos más ricos son dueños del $10 \%$ de Chile, que. 43.000 familias disfrutan de ingresos 
superiores a los $\$ 6.000 .000$ mensuales y que la mayor parte de estas personas son dueños o ejecutivos de grandes empresas. Paradojalmente, nuestros fondos previsionales les proporcionan capital a estos grupos para controlar las empresas y pagarse remuneraciones altísimas, incluso para el estándar europeo o norteamericano.

La participación de las Administradoras de Fondos de Pensiones en las juntas de accionistas de las sociedades sujetas al Título XII del DL. N 3.500, cobra una gran relevancia debido al tamaño relativo de estas empresas y al porcentaje de participación que tienen los Fondos de Pensiones en la propiedad accionaria de las mismas, con una media que alcanza al 18,53\% de las acciones suscritas. Examinemos algunos casos concretos: El porcentaje de acciones adquirido por las AFP alcanza en las empresas que se indican al porcentaje que en cada caso se indica:

TABLA 1: Porcentaje de acciones adquiridos por AFP en sociedades sujetas al Título XII del Decreto Ley 3.500

\begin{tabular}{|l|c|}
\hline Emisor & Total \\
\hline CTC & $25,66 \%$ \\
\hline ENTEL & $25,00 \%$ \\
\hline Endesa & $20,33 \%$ \\
\hline Enersis & $17,23 \%$ \\
\hline lansa & $16,94 \%$ \\
\hline Colbún & $12,45 \%$ \\
\hline SQM & $12,09 \%$ \\
\hline Promedio & $18,53 \%$ \\
\hline
\end{tabular}

Fuente: Información Estadística y Financiera, SAFP [http://www.safp.cl/inf_estadistica/index.html] [1-6-2007]

En sociedades no sujetas al Título XII, las inversiones de los Fondos de Pensiones son menores, básicamente debido a que corresponden a sociedades concentradas, con un acceso más restringido a su propiedad, y a que los límites de inversión autorizados por emisor son también menores. La participación de todas las Administradoras de Fondos de Pensiones en este tipo de sociedades alcanza una media del 5,58\% del capital suscrito, destacando las inversiones en las siguientes sociedades:

TABLA 2: Porcentaje de acciones adquiridos por AFP en sociedades no sujetas al Título XII del Decreto Ley 3.500

\begin{tabular}{|l|c|}
\hline Emisor & Total \\
\hline Masisa & $25,99 \%$ \\
\hline Cristales & $23,48 \%$ \\
\hline Conchatoro & $22,32 \%$ \\
\hline Intasa & $21,68 \%$ \\
\hline Cintac & $21,53 \%$ \\
\hline
\end{tabular}

Fuente: Información Estadística y Financiera, SAFP

[http://www.safp.cl/inf_estadistica/index.htm] [1-6-2007] 


\subsubsection{Participación de AFP en elecciones de Idirectorio}

Estas entidades participaron en las elecciones de directorio correspondientes a 29 sociedades anónimas, dando su apoyo a 33 candidatos, para un total de 51 cargos. Fueron elegidos 28 de los 33 candidatos (85\%), ocupando un total de 33 cargos (65\%) (SAFP, 2006b).

\subsubsection{El peligro para la democracia}

El cientista político Genaro Arriagada Herrera ha escrito: "la concentración de medios de comunicación no es un nuevo fenómeno característico de las sociedades modernas- Lo nuevo es la casi incestuosa relación que se ha desarrollado entre la política y los medios de comunicación. Los políticos usan (y abusan) de los medios para promocionar sus intereses políticos. Hoy es virtualmente imposible conseguir el apoyo sin la ayuda de ellos. Los propietarios de los medios de comunicación los utilizan para promover y defender sus propios intereses políticos, toman ventaja de los políticos de turno para hacer realidad sus intereses empresariales". Citando "La Paradoja de la Libertad" de Karl Popper agrega:"la libertad, si es ilimitada, se anula a sí misma. La libertad ilimitada significa que un individuo vigoroso es libre de asaltar a otro débil y de privarlo de su libertad" (Arriagada, 2006).

Donde la libertad económica fuera absoluta "los ciudadanos económicamente fuertes son libres de atropellar a los económicamente débiles y de robarles su libertad La libertad económica ilimitada puede resultar tan injusta como la libertad física ilimitada. Si el Estado limita sus actividades a la supresión de la violencia y a la protección de la propiedad Seguirá siendo posible que una minoría económicamente fuerte explote a la mayoría de los económicamente débiles" (Arriagada, 2006).

La extrema libertad económica de las empresas que controlan medios de comunicación está transformándose en un verdadero e inminente peligro para la libertad de prensa. El grado de concentración de poder que ya se ha alcanzado : Argentina, 64\%; Bolivia 70\%; Brasil, 33\%; Chile, 75\%; Colombia, 65\%; México, 45\%; Uruguay, 94\%; Venezuela, 70\%. Arriagada (2006) señala que otra amenaza a la libertad de expresión "es la arbitrariedad de muchos empresarios que creen que al colocar sus avisos tienen derecho a influir sobre la línea editorial del medio de comunicación con que contratan. 0, peor, que por la vía de la discriminación publicitaria pueden sacar del mercado a quienes disienten de su ideología o de sus intereses, Intentando reducir el pluralismo del sistema de medios de comunicación". El autor indicado denuncia: "Algunos de estos grandes avisadores quieren asumir, aunque por otros medios, algunas de las funciones que antes se habían arrogado las dictaduras. Por ejemplo, censura o tratar de impedir que se escuchen voces y puntos de vista distintos a los propios". Y agrega que hay una amenaza a la libertad de prensa que se produce "cuando 
el grueso del empresariado se abanderiza con una posición política, cuando usan sólo uno o dos medios de comunicación para el avisaje publicitario, limitando el debate público y perdemos la oportunidad de escuchar a los que no acceden a esos medios".

Basta examinar quienes controlan los canales de televisión, la mayoría de las cadenas de radio, los medios de prensa escrita para darse cuenta que estos importantes formadores de opinión son manejados por los grandes conglomerados empresariales, usando precisamente la influencia que el manejo de nuestros recursos les otorga. No debemos olvidar que el Ministro de Hacienda administra un Presupuesto Nacional cercano a los U\$38.000.000.000, y bajo el estricto control del Parlamento, la Contraloría y los medios de comunicación. En cambio 6 Gerentes generales de AFP administran U\$ 100.000.000.000 sin más control aparente que directorios integrados por los propios interesados o sus mandatarios, sin perjuicio del papel profesional de la SAFP.

Ningún titular ha merecido, por ejemplo, la resolución № 010 de 17 de enero de 2007, en la cual se censura por escrito, vaya sanción, al Director de la AFP Santa María, Daniel Tapia De la Fuente por " adquirir activos de baja liquidez estando esto prohibido" (SAFP. 2007a) o la resolución No 011 de 23 de enero de 2007, en la que se censura al Director de la AFP Habitat S.A., don José Antonio Guzmán Matta, porque "vendió 2.000 unidades del Bono BSCB10705 a través de Inmobiliaria Los Pajaritos Ltda., dentro de los cinco días siguientes a la adquisición que de ese mismo activo hicieron los Fondos de Pensiones de Hábitat, a un precio de venta superior al precio ponderado existente en los mercados formales al día anterior al de la adquisición" (SAFP, 2007b). Esos dos ejemplos nos permiten observar que el uso indebido de información privilegiada no es exclusivo de Sebastián Piñera. Incluso los propios abogados de este destacado personero público denuncian que hay más de 500 personas que han hecho lo mismo?

\subsubsection{La compra de influencia política}

Esos sectores empresariales, mediante aportes a las campañas electorales chilenas y a la incorporación de políticos destacados a los directorios de las AFP o de las empresas que ellos controlan, buscan ampliar su ya extensa influencia. Un estudio del investigador del CEP Salvador Valdés, algunas de cuyas conclusiones principales fueron publicadas en el diario La Tercera del 21 de Enero de 2007, concluye que hubo un aporte del sector empresarial para las campañas electorales del 2005 , ascendente a $\$ 13.700 .000$, lo que representó un 31

2 El autor hace referencia al caso del político y empresario, Sebastián Piñera, sancionado, recientemente, por la Superintendencia de Valores y Seguros por comprar acciones de una aerolínea a un menor precio del que tendrían en días posteriores, gracias al uso de información privilegiada (Nota del Editor). 
$\%$ del total de los gastos reconocidos. Si se parte del concepto común que esto es sólo parte del iceberg, debemos prestarle especial atención, ya que uno de los patrimonios del país, es tener, todavía, una clase política mayoritariamente honesta.

\section{Propuestas para debatir la reforma previsional}

\subsection{Mantener y ampliar el Sistema de Pensiones Público, de reparto solidario, sin fines de lucro que administra hoy el INP y las cajas de las instituciones armadas}

Las reformas que se han implementado en la mayoría de los países mantienen el sistema de reparto y le incorporan modalidades para superar los desafíos que las tasas demográficas decrecientes les presentan, como en Europa. Asimismo, recogiendo las opiniones de los más calificados expertos, mantienen un régimen de recaudación centralizado lo que significa un ahorro considerable, sin perjuicio de permitir la participación de empresas privadas en diverso aspectos, como por ejemplo, las licitaciones en que diversos Fondos de Inversión compiten para captar esos recursos. El Consejo de Seguridad Social de los Estados Unidos ha constatado que: "Los costos administrativos en un esquema de gestión centralizada, en un lapso de 40 años, reducirían la cuenta individual en un $2 \%$. En cambio en un sistema de cuentas descentralizado de cuentas individuales, con varias entidades financieras con opciones amplias de inversión, los costos administrativos reducirían las cuentas individuales en el mismo plazo de 40 años en un 20\%" (Orszag y Stiglitz, 1999).

Al mismo tiempo, en este sistema de reparto, los costos de administración que en la actualidad superan el $22 \%$ mensual en las AFP, se reducirían a menos de la mitad. Debe tenerse presente que esta opción sería absolutamente voluntaria, ya que actualmente la tasa de cotización es cercana al $20 \%$, casi un $8 \%$ más cara que la de la AFP. Lo atractivo de la propuesta es que ella permitiría obtener pensiones casi el doble de las actuales en las AFP y facilitaría la implementación de políticas que impidan la concentración de poder económico.

El proyecto del Gobierno no contempla modificación de la situación excepcional de las Fuerzas Armadas ni amplia las opciones para los trabajadores que deseen volver o integrarse a otro sistema.

\subsection{Establecer un segundo piso previsional administrado por Corporaciones sin fines de lucro o por las actuales AFP}

El Banco Mundial ha incorporado la terminología de los pilares y el Gobierno ha asumido la concreción de un primer pilar no contributivo, es decir, sin aportes de la persona beneficiaria, financiado exclusivamente con fondos públicos. Se trata de una iniciativa muy valiosa y que merece pleno respaldo, que debe ser perfeccionada de manera que no sea discriminatoria 
para los trabajadores de las clases medias y para que no produzcan un efecto perverso no deseado.

En efecto si, una persona puede recibir una pensión de $\$ 75.000$ sin cotizar un solo mes, bastando que pertenezca al sector del $60 \%$ más pobre, lo que es justo y necesario, la señal podría ser equivocada para un trabajador que gana entre $\$ 400.000$ y $\$ 1.000 .0000$ que obtendría jubilaciones un poco superiores a $\$ 200.000$, después de 40045 años de cotizar el $12 \%$ de su remuneración mensual, esto es, entre $\$ 44.000$ y $\$ 120.000$. Si se genera un piso común financiado con impuestos y con un porcentaje de la cotización de los trabajadores se favorece la solidaridad y una mejor pensión para amplios sectores del país.

El segundo pilar, contributivo, se formaría con las aportaciones de los trabajadores y de los empleadores, lo que permitirá estimular el trabajo formal, las cotizaciones periódicas y permitiría una pensión sustancialmente más alta que las actuales, si se logra reducir a la mitad, por lo menos, el abusivo cobro actual de las AFP. La existencia de entidades sin fines de lucro es una realidad y no una abstracción, como se demuestra con el funcionamiento positivo de las Cajas de Compensación y las Mutuales de Seguridad, de modo que permitir el funcionamiento de algunas especializadas en Ahorro previsional es perfectamente posible. Para las personas que quieran optar por las actuales AFP, existiría, como corresponde, libertad de opción. El proyecto presentado al Congreso no considera ninguna norma al respecto.

\subsection{Establecer la obligatoriedad del aporte patronal, tal como ocurre en todos los países del mundo, con la excepción de Chile, Perú y Bolivia}

El Gobierno ha dado señales que estaría a poner de cargo del empleador el pago del Seguro de Invalidez y Sobrevivencia, cuyo costo no supera el $1 \%$ de las remuneraciones. En la actualidad existe aporte patronal desde la década de 1960 para Accidentes del Trabajo, entre el $1,5 \%$ y el $3 \%$, aproximadamente, para trabajos pesados y para el subsidio de cesantía, establecidos bajo los primeros gobiernos concertacionistas, sin que la economía haya sufrido deterioro alguno por esta causa. Al contrario, ha sido un factor de desarrollo positivo en diversos ámbitos. Entre un 2 y un 10\% adicional, de manera progresiva, deducible de impuestos, con subsidios para jóvenes y para cooperativas y medianas y pequeñas empresas, no generaría ningún problema insoluble.

\subsection{El Estado se hace cargo del aporte patronal de las Cooperativas pequeñas y medianas, de micro y pequeñas empresas}

Se han dictado diversas normas para apoyar a este sector, las que son aún insuficientes. El Gobierno contempla en su proyecto un subsidio para jóvenes que cubriría casi la totalidad de sus cotizaciones, lo que beneficia a los jóvenes y a las pequeñas y medianas empresas. 


\subsection{Crear una AFP del Estado, sujeta a las mismas normas que las otras AFP}

Si las personas son libres para escoger entre un Banco del Estado y los Bancos privados, entre Instituciones de Salud Previsional (ISAPRES) o FONASA, ¿Por qué no se puede tener la libertad para escoger entre este tipo de opciones en la Previsión? Una entidad de este tipo, administrada sin fines de lucro, reduciría enormemente los costos, y podría ser de gran utilidad para evitar la concentración económica, el control por grupos económicos de los recursos de los trabajadores, reduciendo el riesgo de influencia monocolor de la prensa y favoreciendo la transparencia en la actividad política. Sus personeros tendrían dependencias del Ministerio del Trabajo y podría atizarse todo el instrumental de fiscalización parlamentaria y de medios que existe, si se llegara a detectar algún abuso de su posición. La integración en su directorio de representantes de los aportantes sería un factor adicional de equilibrio.

Por su parte, la asociación de AFP ha financiado una campaña muy fuerte contra la idea de una AFP del Estado. Junto con publicar críticas conocidas al antiguo sistema, afirma "Crear una AFP del Estado provocaría enormes desincentivos a la incorporación de nuevas administradoras a esta industria y conduciría a una concentración de la oferta, ya que una institución estatal dispone de herramientas que ningún particular tiene, lo que deteriora el funcionamiento del mercado"(AAFP, 2007).

Llama la atención esta argumentación, por cuanto es público y notorio, que estando todas las condiciones abiertas para la creación de más AFP por los interesados, la asociación eluda la realidad de que existen sólo 6 y que hoy sólo 3 de ellas concentran un porcentaje superior al $70 \%$ de los afiliados. Su otra crítica, es también muy débil, ellas afirman: "La intromisión del Estado en actividades económicas genera competencia desleal, porque se utilizan recursos fiscales que no tienen igual costo financiero a los que tiene acceso el sector privado". El Banco del Estado no es el más grande del sistema y nadie lo acusa de conducta monopólica. Una tercera crítica es aún más débil: "La mayoría de las veces que el sector público emprende alguna actividad económica, lo hace sobre la base de un objetivo socialmente deseable y, en ese marco, no cuentan mucho los costos ni el rédito económico". No cabe duda que las pensiones para los trabajadores es un objetivo prioritario para el Estado, según lo dispone la Constitución y los acuerdos internacionales. No vale la pena perder tiempo con el resto del argumento, que acusa al Estado de usar infraestructura estatal, como oficinas, personal y tecnología, generando un claro subsidio, en detrimento de competidores privados. Recibir subsidios del Estado para ellos, es apropiado, usar bienes del Estado para satisfacer una necesidad tan justificada e importante, les parece "competencia desleal" (AAFP, 2006).

Existen señales positivas respecto a la posibilidad de admitir la creación de una AFP estatal, ya que la idea cuenta con el apoyo mayoritario de los partidos de la Concertación y 
el Gobierno estaría dispuesto a considerarla, aunque dentro de la opción abierta a todos los Bancos, lo que nos parece claramente inconveniente, por cuanto las AFP deben tomar resoluciones a favor de los afiliados y no de sus propietarios, sean estos bancos o compañías de seguros. No obstante lo anterior, junto con producir un efecto negativo por la disputa comercial que se generará, el sólo hecho que el Estado, participe, aunque sea a través de esa entidad financiera, pudiera ser un paso importante, si el equipo económico cambia su actual posición contraria.

\subsection{Participación de trabajadores y empleadores en los Directorios de las AFP}

Si ambos sectores aportan, parece de elemental justicia que ambos sectores estén representados en la proporción que corresponda en los Directorios de las AFP, lo que se fundamenta en el pleno respeto del derecho de propiedad, establecido en la Constitución. El Proyecto del Gobierno sólo crea una Comisión de Usuarios, al igual que la entidad que existe en las normas legales que crearon el subsidio de cesantía, lo que es absolutamente insuficiente.

\subsection{Prohibir participación de AFP en la elección de directores de empresas}

Los datos entregados en este artículo y muchos antecedentes más, muestran el tremendo poder que los administradores de AFP tienen en empresas muy importantes, lo que favorece la concentración del poder en pequeños grupos y estimula la injusta distribución del ingreso. Esta opción permite a los dueños de esas empresas tener socios confiables, que no emigrarán en una situación de baja transitoria, como ocurre habitualmente en las actividades comerciales. Debe tenerse en cuenta el daño, casi definitivo que podría acontecer si un grupo controlador de AFP decide vender en un momento de crisis pasajera las acciones de una empresa, lo que podría acelerar su desplome y hacer imposible su recuperación. Si bien es cierto, muchos empresarios optan por esta forma de inversión para no presentar altos márgenes de endeudamiento, es más seguro y estable emitir bonos, que con los resguardos debidos, puedan ser adquiridos por los Fondos Previsionales, estimulando la inversión y el desarrollo de la economía. Esta medida que busca evitar mantener la indebida influencia de los dueños de las AFP en las empresas no ha sido considerada por el Gobierno.

\subsection{Obligación de invertir los recursos de las AFP en Chile}

El Banco Mundial (2006) señala lo sorprendente que es que Chile sea exportador de capitales, con porcentajes equivalentes a los que se manejan por países desarrollados. "Mientras que los gobiernos de la mayoría de los países en desarrollo luchan por atraer e incrementar la inversión privada, los activos del sistema de pensiones chileno, como porcentaje 
del PIB, rivalizan con los de los Estados Unidos y el Reino Unido". Es la misma sorpresa que sentimos muchos cuando constatamos que las tremendas carencias existentes en infraestructura en nuestro país podrían verse subsanadas utilizando fondos frescos, de largo plazo y a tasas muy convenientes. Mencionemos dos ejemplos: Si Chile formara una Corporación con Bolivia, Venezuela, Perú y Ecuador, por mencionar algunos casos, que implementara el anillo energético propuesto por el ex Ministro de Economía Jorge Rodríguez y planteado actualmente por el Presidente de Venezuela, Hugo Chávez, se podrían invertir miles de millones de dólares en los depósitos de gas de Bolivia que no se explotan por falta de capitales.

Los obstáculos reales existentes por temas históricos del pasado, podrían ser superados por las coincidencias entre los gobernantes de Bolivia, y Venezuela, más las buenas relaciones con Ecuador y otros países si se acepta el hecho práctico que las relaciones internacionales no deben definirse por las coincidencias o discrepancias entre los gobiernos, sino por los intereses más profundos de los pueblos, entre los cuales el de paz, integración, justicia social y desarrollo sostenible son prioritarios.

El proyecto va en la dirección contraria a toda máquina, sin mayores protestas de los parlamentarios $\mathrm{u}$ otros actores.

\subsection{Crear un Fondo de Apoyo a las Cooperativas y Pymes}

Salvo las normas mencionadas para subsidiar las cotizaciones de los jóvenes, no hay más normas que estimulen este importante sector.

\subsection{Eliminar la Comisión fija}

Esta es una de las principales razones para que el costo sea mayor para los que ganan menos. En efecto, no hay duda que un costo de $\$ 600$ para un afiliado que cotiza $\$ 12.700$ es mucho más relevante que para uno que cotiza por $\$ 1.000 .000$. El proyecto, acertadamente la elimina, cumpliendo con una promesa del programa de la Concertación de año 1989, pero las AFP se preparan para subir los costos por otra vía.

\subsection{Reconocer un año de imposiciones a las madres que trabajan por cada hijo}

Esta medida busca disminuir el impacto negativo que el sistema recoge respecto a la desigualdad de género. El proyecto del Gobierno introduce esta positiva medida, pero limitando a los aportes al sueldo mínimo y no al salario real de la trabajadora, lo que afecta a los sectores medio bajos. 


\subsection{Reconocer el derecho de opción del viudo a una pensión de Sobrevivencia 0 a retirar el dinero que le corresponda}

El proyecto pone fin a la injusta discriminación existente para el cónyuge varón, ya que el sistema es privado y cada cónyuge paga su propia previsión. El derecho de opción permite destinar el dinero a una pensión o a pagar una deuda hipotecaria, lo que resulte más conveniente para el beneficiario, ya que no afecta a nadie más y sólo evita pagar obligatoriamente por algo que no se requiere. Las AFP ya anuncian que por esta medida, se incrementará en un $30 \%$ el valor de la prima del Seguro de Invalidez y Sobrevivencia.

\subsection{Reparar el daño previsional que afecta a cerca de 130.000 trabajadores}

Este es un tema recurrente, de absoluta justicia y con propuestas que compensan debidamente el mayor gasto estatal. En efecto, los trabajadores afectados están dispuestos a pagar mensualmente una suma, descontada de sus pensiones, para compensar las menores imposiciones hechas en el sistema AFP, respecto del Instituto de Normalización Previsional (INP). Si esta medida se complementara con seguros dé gravamen, como los que existen actualmente en la actividad financiera, se minimizarían lo eventuales costos asociados. Los gobernantes han buscado soluciones por otras vías. Durante el Gobierno del Presidente Lagos, se ofreció una suma de $\$ 50.000$ mensuales a los que jubilaran, de manera vitalicia. En la actualidad se ofrecen Bonos a profesores y empleados públicos, cotizantes de las AFP que van desde los $\$ 10.000 .000$ a $\$ 20.000 .000$, por una sola vez. Estas medidas son positivas pero no resuelven la legítima demanda de una manera adecuada.

\subsection{Enfrentar una reforma justa y apropiada al sistema de las FFAA}

A pesar que el propio José Piñera ha escrito, ahora, que es necesario enfrentar el déficit que allí se genera y que supera los U\$1.000.000.000 anuales, nada hay en el proyecto del Gobierno. La Revista Qué Pasa, del 14 de mayo de 2000, daba antecedentes muy llamativos, los que no se abordan habitualmente en los medios de comunicación chilenos.

Recordemos algunos de esos antecedentes. La periodista María Eugenia Larraín, informaba que el tema de una creciente carga fiscal por efectos de la previsión de las Fuerzas Armadas, que ella cuantificaba en su nota en una cifra superior a los U\$ 1.100.000.000, lo había puesto en discusión el denominado "padre del actual modelo de pensiones", José Piñera el que en Marzo del 2000 escribió en la revista virtual Economía y Sociedad que el sistema de Jubilación de los uniformados estaba totalmente quebrado. Para justificar su afirmación, el señor Piñera señalaba que el hoyo era creciente para el Fisco ya que en 1996 el compromiso económico del Estado ascendió a los US \$ 866 millones y el 2000 ya superaba los US \$ 1.000 millones. 
Otro experto citado en el artículo que citamos, Eduardo Santos, señalaba que los uniformados jubilan en promedio a los 47 años, con una pensión equivalente al $75 \%$ de su sueldo, lo que permitía que en esa fecha, un Coronel en retiro recibiera unos $\$ 800.000$ mensuales de pensión.

\subsection{Reducir el plazo exigido para optar a la pensión mínima con garantía estatal}

Las cifras eran elocuente, los 20 años exigidos no eran alcanzables por una abrumadora cantidad de chilenos, los que sólo cotizan en promedio, 4,9 meses en el año, siendo peor aún, la situación de las mujeres. Ahora se ha eliminado ese plazo de cotizaciones y reemplazado por años en Chile, con un mínimo de 5 en el país ante de jubilar. Esta medida es ampliamente positiva y sólo debe evitarse el efecto no deseado que hemos mencionado antes.

\subsection{Igualar trato tributario de Fondos AFP con inversionistas privados}

En esta materia hay acuerdo de las AFP, ya que al igual que con otras medidas, ellas no ponen un peso, es el Estado el que debe asumir el costo, que en esta materia parece justo, ya que los Fondos de Pensiones no pueden recuperar el Crédito Fiscal por los Impuestos ya pagados por las sociedades anónimas al distribuir dividendos. Como se sabe en nuestro país, los impuestos son de cargo de las personas y no de las empresas., lo que implica que el Impuesto de Primera Categoría que se aplica a las utilidades de estas entidades, es un impuesto a cuenta del Global Complementario de los dueños de la sociedad, lo que les permite descontarlo en la declaración anual de impuestos que se realiza todos los años en el mes de abril.

Es un hecho que los Fondos de Pensiones reciben normalmente diversas cantidades por concepto de dividendos, no obstante lo cual no se les da un trato similar a otros accionistas y se les impide recuperar para los afiliados el Impuesto de Primera Categorías. Las publicaciones de la asociación de AFP afirman que esa discriminación ha generado perjuicios a los Fondos del orden de los US \$1.600 millones. Esta entidad empresarial sostiene que la inequidad se origina en la Ley $N^{\circ} 18.398$, de 1985, la que autorizando la inversión de parte de los ahorros de los Fondos en acciones de sociedades anónimas abiertas, no incluyó el derecho a este crédito. De acuerdo a los antecedente proporcionados por la Asociación de AFP, al mes de Junio del 2006, el 14,33\% de los Fondos de Pensiones, US \$10.800 millones, se encontraban invertidos en 110 sociedades anónimas abiertas, las que pagaron a los Fondos, en el primer Semestre del 2006, US \$220 millones por concepto de dividendos. La Asociación de AFP sostiene que "desde 1985 a la fecha los dividendos recibidos por los Fondos de 
Pensiones han alcanzado a US $\$ 4.800$ millones, dejando de percibir por concepto de Crédito no Recuperado la cantidad de US \$ 876 millones" (AAFP, 2006).

El debate sobre este tema continuará en lo próximos meses, ya que la Cámara de Diputados ha aprobado el proyecto con algunas modificaciones y a partir del mes de Septiembre se comenzará a discutir en el Senado.

\section{Referencias bibliográficas:}

AAFP - Asociación de Administradoras Fondos de Pensiones. 2006. Trabajadores y Empresarios Piden Solucionar Daño Tributario contra Afiliados de AFP. Serie de Estudios Asociación AFP No 58 Octubre.En

http://www.fiap.cl/prontus_noticia/site/artic/20070104/asocfile/20070104113348/estudi o58.pdf 6-5-2007.

2007. ¿Qué Aporta una AFP Estatal al Esfuerzo de Ahorro para Pensiones de los Trabajadores?. Serie de Estudios Asociación AFP N ${ }^{\circ} 60$ Febrero. En http://www.fiap.cl/p4_boletin/site/artic/20070221/asocfile/ASOCFILE0120070221145 309.doc 15-3-2007.

Arellano, Juan Pablo. 1981. Elementos para el Análisis de la Reforma Previsional Chilena, Coleccion Estudios CIEPLAN 6.

Arriagada, Genaro. 2006. Cuando el Mercado Ahoga la Libertad de Prensa. Informe $N^{\circ}$ 570 Asuntos Públicos. En http://www.asuntospublicos.org/informe.php?id=3585 4-32007.

BM - Banco Mundial. 2006. Chile. Opciones para Mejorar la Seguridad de Ingresos de la Tercera Edad. En http://www.consejoreformaprevisional.cl/documentos/audiencias/1704-2006-bancoMundial.pdf 1-6-2007.

CARP - Consejo Asesor Presidencial para la Reforma Previsional. 2006. Derecho a una Vida Digna en la Vejez. Hacia un Contrato Social con la Previsión en Chile. Volumen I. Diagnóstico y Propuesta de Reforma. En http://www.consejoreformaprevisional.cl/view/informe-capitulos.asp 1-6-2007.

Novoa, Patricio. 1977. Derecho de la Seguridad Social. Santiago: Editorial Jurídica de Chile.

OIT - Organización Internacional del Trabajo. 1993. Informe de la Comisión de Expertos OIT. Informe III A. Ginebra: OIT.

--------. 2002. Seguridad Social: Un Nuevo Consenso. Ginebra: OIT.

Orszag, Peter y Joseph Stiglitz. 1999. Un Nuevo Análisis de la Reforma de Pensiones: Diez Mitos Sobre los Sistemas de Seguridad Social. Trabajo presentado en la Conferencia "Nuevas Ideas sobre la Seguridad Social", 14-15 Septiembre, Washington, Estados Unidos. En http://www.redsegsoc.org.uy/1_Jor_Diez-Mitos.htm 1-4-2007.

Piñera, José. 1991. El Cascabel al Gato. Santiago: Zig-Zag.

SAFP Superintendencia de Administradoras de Fondos de Pensiones. 2006a. Boletín Estadístico SAFP $N^{o}$ 195. Santiago: SAFP. 
2006b. Participación de las Administradoras de Fondos de Pensiones en Juntas Ordinarias y Extraordinarias de Accionistas, Juntas de Tenedores de Bonos y Asambleas Ordinarias y Extraordinarias de Aportantes de Fondos de Inversión. En http://www.safp.cl/p4_comunicados/site/asocfile/ASOCFILE120060828112251.pdf 4-3 -2007a. Resolución $\mathrm{N}^{\circ}$ 10, 17 de enero.

2007b. Resolución $\mathrm{N}^{\circ}$ 11, 23 de enero.

2007c. Boletín Estadistico SAFP $N^{\circ} 197$. Santiago: SAFP.

Ricardo Hormazábal S. es Profesor Adjunto del Departamento de Gobierno y Gestión Pública del Instituto de Asuntos Públicos de la Universidad de Chile. Es Abogado de la misma casa de estudios. Ha sido diputado, senador, embajador y Presidente de la Democracia Cristiana.

E-mail: rhormaza@uchile.cl 